\title{
Researches on the Influence of Blasting of Newly Built Tunnel on the Existing Tunnel Structure with Small Cross Angle
}

\author{
Xian Du, ${ }^{1}$ Qinghua Xiao $\mathbb{D}^{2},{ }^{2}$ Congming Li, ${ }^{2}$ Qiang Xiong, ${ }^{2}$ and Jianyou Yu ${ }^{1}$ \\ ${ }^{1}$ Yanchong Expressway Construction Office, Hebei Expressway Group Co., Ltd., Shijiazhuang 050000, China \\ ${ }^{2}$ School of Civil Engineering, Southwest Jiaotong University, Chengdu 610031, China \\ Correspondence should be addressed to Qinghua Xiao; xqhbp@swjtu.edu.cn
}

Received 23 July 2021; Revised 22 September 2021; Accepted 5 November 2021; Published 25 November 2021

Academic Editor: Qian Chen

Copyright (c) 2021 Xian Du et al. This is an open access article distributed under the Creative Commons Attribution License, which permits unrestricted use, distribution, and reproduction in any medium, provided the original work is properly cited.

In recent years, with the increasement of the railway expansion projects, the blasting damage has caused great threat to the safety of the existing tunnel structure. However, few researches are carried out on the influence of tunnel blasting construction on existing small-angle crossing tunnel structure. In this study, the dynamic response of existing tunnel structure to the blasting activities in newly built tunnel is analyzed by numerical simulation. From the comparison of vibration velocity, lining stress, and the displacement of the existing tunnel structure, the blasting methods, surrounding rock condition, cross angle, and clear distance are proven to be the highly correlated factors for the dynamic response of the existing tunnel to blasting. Then, combined with the analytic hierarchy process, the vibration velocity is selected as the optimal index to indicate the dynamic response to blasting activities.

\section{Introduction}

Nowadays, the railway has become one of the important modern transportations which is related to the national economy and people's livelihood $[1,2]$. With the construction of the large-scale transport network, it is unavoidable to appear more and more spatially crossing railway tunnels with very small crossing angles, especially for the high-speed railways whose lines must be as straight as possible [3,4], for example, in the new Guiyang-Guangzhou Railway, the Sizhai Tunnel goes under the Ruipo Tunnel, with a plane crossing angle of $22^{\circ}$ and the minimum vertical clear distance of $23.0 \mathrm{~m}$ [5]. In the Wenzhou-Fuzhou Railway, the newly built Guantouling Tunnel goes under a tunnel of Wen-Fu Expressway, with a plane crossing angle of $36^{\circ}$ and the minimum vertical clear distance of $2.91 \mathrm{~m} \mathrm{[6].} \mathrm{Under} \mathrm{such} \mathrm{extreme} \mathrm{space} \mathrm{conditions,}$ the commonly used construction method will inevitably affect the surrounding structures $[7,8]$. Hence, it is necessary to evaluate the influence of the blasting activities on the existing tunnel structures.

In the few decades, amounts of researches have been carried out to study the response of structure to the blasting activities in tunnel constructions, such as the field tests, indoor experiments, numerical simulation, artificial intelligence [9-17]. Hong [18] studied the dynamic impact of cross section blasting excavation at intersections on the lining of existing tunnels, and the results showed that the maximum vibration velocity and the maximum tensile stress of each section of the lining were greatly reduced out of the range of $\pm 8 \mathrm{~m}$ at the cross section, and the lining structure was more sensitive to blasting within the range of $\pm 8 \mathrm{~m}$ around the blasting source. Liu et al. [19] established a finite element model of the upper and lower crossing tunnels and extracted the velocity-time history curve and equivalent stress-time history curve of each monitoring point, and the results indicated that the vibration velocity distribution of each point was basically consistent with the monitored vibration velocity; combined with the equivalent stress criterion, the vibration velocity of the critical mass point can be selected to ensure the safety of tunnel structure. Song et al. [20] studied the dynamic response law of the surrounding rock during the excavation of a large section tunnel by the virtue of portable electric spark source and found that the blasting process of the back tunnel has a greater impact on 
the stability of the surrounding rock, while the surrounding rock at the oblique back of the tunnel is less sensitive to excavation and blasting vibration and is affected by the blasting process for longer time. In summary, the dynamic response characteristics of cross-tunnel blasting have attracted the attention of researchers, but most of them focus on the vibration velocity, without considering the stress and displacement of the existing railway tunnel. Therefore, to ensure the safety of the existing railway tunnel structure, it is necessary to comprehensively analyze the regular changes of its vibration velocity, displacement, and stress under different influencing factors.

Moreover, the partitioning methods also play vital role in the study of the impact of tunnel blasting [21, 22]. In the Guidelines for the Approaching Construction of Existing Railway Tunnels and the Guidelines for the Approaching Construction of Highway Tunnels, the problems of proximity construction were systematically discussed, and the concepts of proximity and influence zoning were clearly put forward. The latest Chinese monographs and specifications also contain relevant research content on the proximity construction of different building types. The Code for Design of Highway Tunnels clarifies the content of small clear distance tunnels and proposed the general process and methods of design and construction. Zhang et al. [23] established the tunnel construction impact zone of adjacent buildings according to the change trend of the stress state of the surrounding rock; based on the stress condition, the construction of new tunnels adjacent to the existing buildings can be divided into three types: strong, weak, and noninfluencing zones. Tian et al. [24] selected the ultimate shear strain as the criterion for instability of surrounding rock based on the existing problems of different criteria for instability of surrounding rock, by comparing the tunnels of a single tunnel and adjacent systems with existing urban roads, and taking the difference in safety factor as the threshold of the affected area, a mechanical calculation model for different tunnels near existing urban roads is established. However, the existing researches rarely studied the partitioning methods of dynamic impact zone of railway tunnels.

In this study, the response of existing tunnel structure to the blasting activities was studied by numerical simulation methods, various factors were incorporated into the model under different conditions, and finally various factors are compared to distinguish the optimal indictor for the dynamic response of existing tunnel. The framework of this paper is arranged as follows: Section 2 mainly describes the engineering background, Section 3 introduces the simulation methods blasting in tunnel excavation, Section 4 analyzes the simulation results in various conditions, Section 5 focuses on the determination of optimal indictor of dynamic response to blasting activities, and Section 6 summarizes the whole paper.

\section{Engineering Background}

The Tashi tunnel located in Longquan City (Zhejiang Province) is an important part of the Xianju-Qingyuan expressway. The starting point of the project line is on the left side of the Yuankengling tunnel in Tashi street and connected with the 322nd national highway. The terminal point is located at the intersection of Fangye and Housha road, Jianchi Street. The newly built Tashi tunnel is designed according to the secondary highway standard with designed speed of $60 \mathrm{~km} / \mathrm{h}$. The geometries of tunnel are designed as follows: the length is $1825 \mathrm{~m}$, the width is $12 \mathrm{~m}$, and the clear height is $5 \mathrm{~m}$. More significantly, the Tashi tunnel is located under the Yuankengling tunnel which belong to the existing Quning Railway.

Considering the above complicated conditions, the newly built tunnel passes through the existing tunnel structure with small cross angle, the safety of existing tunnel structure is severely influenced by the excavation of the newly built tunnel, and the impact of the blasting construction of a new tunnel on the existing tunnel structure should be carefully evaluated during construction. Hence, in order to make the effective safety controlling methods, it is necessary to study the various influencing factors on the dynamic response of existing tunnel structure and distinguish the optimal indictor of dynamic response to blasting activities.

\section{Numerical Simulation Methods}

3.1. Simulation of Material in Explosion. Among many numerical simulation methods, ANSYS/LS-DYNA is widely used in blasting simulation because it can be used to calculate the large deformation dynamic response of nonlinear structural materials $[25,26]$. Among them, the simulation of the three materials in the explosion problem, explosives, air, and rock materials, is particularly important.

3.1.1. Explosive Model. The JWL state equation is always used to describe the relationship between the pressure and volume of the detonation product of high-performance explosives, and the specific pressure $P_{e o s}$ of the explosive detonation product can be calculated using the following equation:

$$
P_{\text {eos }}=A\left(1-\frac{\omega}{R_{1} V}\right) e^{-R_{1} V}+B\left(1-\frac{\omega}{R_{2} V}\right) e^{-R_{2} V}+\frac{\omega E_{0}}{V}
$$

where $P_{\text {eos }}$ is the specific pressure, $V$ is the relative volume, $E_{0}$ is the specific internal energy, and $A, B, R_{1}, R_{2}$, and $\omega$ are constants determined by material. The above parameters of explosive used in the current study are listed in Table 1.

3.1.2. Air Model. The air is simulated by *MAT_NULL model, and its pressure can be calculated by the linear polynomial state equation EOS_LINEAR_POLYNOMIAL, as shown in the following equations:

$$
\begin{aligned}
p_{0} & =C_{0}+C_{1} \lambda+C_{2} \lambda^{2}+C_{3} \lambda^{3}+\left(C_{4}+C_{5} \lambda+C_{6} \lambda^{2}\right) E_{1}, \\
\lambda & =\frac{1}{V_{0}}-1,
\end{aligned}
$$

Where $p_{0}$ is the pressure, $E_{1}$ is the internal energy of unit volume, $V_{0}$ is the initial relative volume, and $C_{0}, C_{1}, C_{2}, C_{3}$, 
TABle 1: Parameters of explosive in simulation.

\begin{tabular}{lcccccccc}
\hline Density $\rho_{e}\left(\mathrm{~kg} / \mathrm{m}^{3}\right)$ & Detonation velocity $D_{H}(\mathrm{~m} / \mathrm{s})$ & $A(\mathrm{GPa})$ & $B(\mathrm{GPa})$ & $R_{1}$ & $R_{2}$ & $\omega$ & $P_{\text {eos }}(\mathrm{GPa})$ & $E_{0}(\mathrm{GPa})$ \\
\hline 1000 & 4200 & 211 & 0.18 & 4.20 & 0.90 & 0.15 & 9.70 & 4.19 \\
\hline
\end{tabular}

$C_{4}, C_{5}$, and $C_{6}$ are real constants of the state equation. The above parameters of simulated air are listed in Table 2.

3.1.3. Rock Model. The rock mass adopts *MAT_PLASTIC_KINEMATIC isotropic followup plastic strengthening material mode. Compared with the condition of static load, the mechanical properties of the rock mass under the blasting load have also changed, and the strain rate has been greatly improved. Based on the Symonds-Cowper empirical formula, the model introduces the strain rate amplification factor, defines the element failure keyword *MAT_ADD_EROSION, and defines the rock mass strength as the failure criterion to realize the damage and failure of the rock mass. The yielding stress $\sigma_{y}$ of rock mass can be calculated by

$$
\begin{aligned}
\sigma_{y} & =\left[1+\left(\frac{\dot{\varepsilon}}{C}\right)^{(1 / P)}\right]\left(\sigma_{0}+\beta E_{p} \varepsilon_{p}^{\text {eff }}\right), \\
E_{p} & =\frac{E_{0} E_{\text {tan }}}{E_{0}-E_{\tan }}, \\
\varepsilon_{p}^{\text {eff }} & =\int_{0}^{t} \mathrm{~d} \varepsilon_{p}^{\text {eff }}, \\
d \varepsilon_{p}^{\text {eff }} & =\sqrt{\frac{2}{3} d \varepsilon_{i j}^{p} d \varepsilon_{i j}^{p}},
\end{aligned}
$$

where $\sigma_{0}$ is the initial yielding stress, $E$ is Young's modulus, $\dot{\varepsilon}$ is the loading strain rate, $C$ and $P$ are the constants determined by the strain rate of the material, $E_{p}$ is the plastic hardening modulus of rock mass, $E_{\text {tan }}$ is the tangent modulus, $\beta$ is the influence degree of hardening parameters on isotropic hardening and kinematic hardening, $\varepsilon_{p}^{\text {eff }}$ is the effective plastic strain of rock mass, $t$ is the duration of plastic strain, and $\varepsilon_{i j}^{p}$ is the component of plastic strain deviation of rock mass. The above parameters are shown in Table 3 .

3.2. The Geometries of Models. Considering the research target and the simplification of computational process, the numerical model is designed as follows. According to the influence of tunnel construction, the size of impact area is always regarded as 3 to 5 times the tunnel radius. That is, the existing tunnel influence area is $27.09 \mathrm{~m}$ to $45.15 \mathrm{~m}$. Hence, $40 \mathrm{~m}$ is selected in the simulation. Similarly, the influence area of the new tunnel is calculated as $38.82 \mathrm{~m}$ to $64.70 \mathrm{~m}$, and $50 \mathrm{~m}$ impact zone is considered in the model calculation. Consequently, the simulation model $140.00 \mathrm{~m} \times$ $200.00 \mathrm{~m} \times 124.52 \mathrm{~m}$ is established as shown in Figure 1 . Figure 1(a) is the spatial structure diagram of the model, and Figure 1(b) is the constructed 3-dimensional element model.
As can be seen, the newly built tunnel is located under the existing tunnel, which is consistent with the cases in the practical engineering, and the distance $D$ and cross angle $\alpha$ are set as variables in the simulation, so as to distinguish the influence of the spatial relationship on the dynamic response of the existing tunnel.

3.3. Design of Test Conditions. According to the research purpose of the current study, the blasting methods of tunnel, the condition of surrounding rock, and the relative position (clear distance and angle of the spatial intersection) are selected as the main influencing factors of the dynamic response to the tunnel blasting. Therefore, based on the above influencing factors, the test conditions are designed as shown in Table 4, and the ANSYS/LS-DYNA blasting dynamic software is used to perform numerical simulation to analyze the sensitivity of each influencing factor, which will further provide parameter indicators for the indication of dynamic response. It should be noted that the values of maximum charge per delay of each blasting method are directly calculated from the blasting schemes. The simulation is implemented when the tunnel excavation face is located under the existing tunnel.

\section{Results and Analysis}

The above research simulates the blasting activities of new tunnel under various conditions, such as the blasting method, the surrounding rock condition, clear distance, and cross angle. It should be noted that the effectiveness of the adopted numerical methods has been proved in several published literatures, and the simulation results are consistent with the monitored results in practical engineering. Then the response of existing tunnel to the blasting is analyzed from the aspects of vibration velocity, lining stress, and structure displacement.

4.1. Different Blasting Methods. The full-section method and bench method are two frequently used construction methods for the excavation of mountainous tunnel. The main difference between such two methods is the maximum charge per delay, that is, the energy released in a short time.

Firstly, the vibration velocity-time history of different parts of the existing tunnel structure is extracted from the simulation results, as shown in Figure 2. The envelope diagram of the vibration velocity of existing tunnel is shown in Figure 3. It could be found that the maximum vibration velocity of the existing railway tunnel structure for fullsection and bench method both appeared on the tunnel left foot, with the values of $8.08 \mathrm{~cm} / \mathrm{s}$ and $5.30 \mathrm{~cm} / \mathrm{s}$, respectively. The minimum vibration velocity for such two methods appeared on the right arch waist of the tunnel, with the 
TABle 2: Parameters of air in simulation.

\begin{tabular}{lccccccccc}
\hline Density $\left(\mathrm{kg} / \mathrm{m}^{3}\right)$ & $C_{0}$ & $C_{1}$ & $C_{2}$ & $C_{3}$ & $C_{4}$ & $C_{5}$ & $C_{6}$ & $E_{1}(\mathrm{MPa})$ & $V_{0}$ \\
\hline 1.29 & 0 & 0 & 0 & 0 & 0.40 & 0.40 & 0 & 0.25 & 1.00 \\
\hline
\end{tabular}

TABLE 3: Parameters of rock in simulation.

\begin{tabular}{lcccccccc}
\hline$\rho_{0}\left(\mathrm{~kg} / \mathrm{m}^{3}\right)$ & $E(\mathrm{GPa})$ & $v$ & $\sigma_{0}(\mathrm{MPa})$ & $E_{\tan }(\mathrm{GPa})$ & $C\left(\mathrm{~s}^{-1}\right)$ & $P$ & $\sigma_{c}(\mathrm{MPa})$ & $\sigma_{t}(\mathrm{MPa})$ \\
\hline 2900 & 20.50 & 0.26 & 75.00 & 15 & 2.63 & 3.96 & 185.00 & 5.20 \\
\hline
\end{tabular}

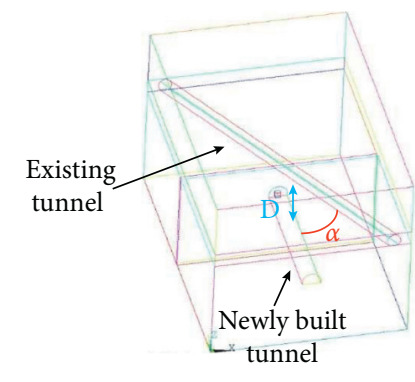

(a)

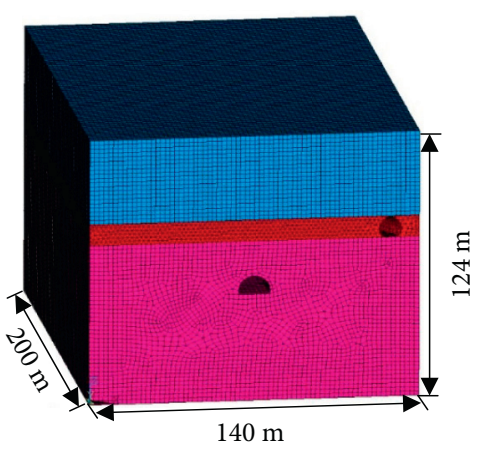

(b)

Figure 1: The geometries of the numerical model.

Table 4: The arrangement of testing conditions.

\begin{tabular}{lccccc}
\hline No. & Maximum charge per delay $Q(\mathrm{~kg})$ & Surrounding rock & Clear distance $D(\mathrm{~m})$ & Cross angle $\alpha\left(^{\circ}\right)$ & Blasting methods \\
\hline 1 & 26.50 & III & 16.90 & $30^{\circ}$ & Full-section method \\
2 & 13.14 & III & 16.90 & $30^{\circ}$ & Bench method \\
3 & 13.14 & IV & 16.90 & $30^{\circ}$ & Bench method \\
4 & 13.14 & III & 16.90 & $15^{\circ}$ & Bench method \\
5 & 13.14 & III & 16.90 & $45^{\circ}$ & Bench method \\
6 & 13.14 & III & 8.45 & $30^{\circ}$ & Bench method \\
7 & 13.14 & III & 25.35 & $30^{\circ}$ & Bench method \\
\hline
\end{tabular}

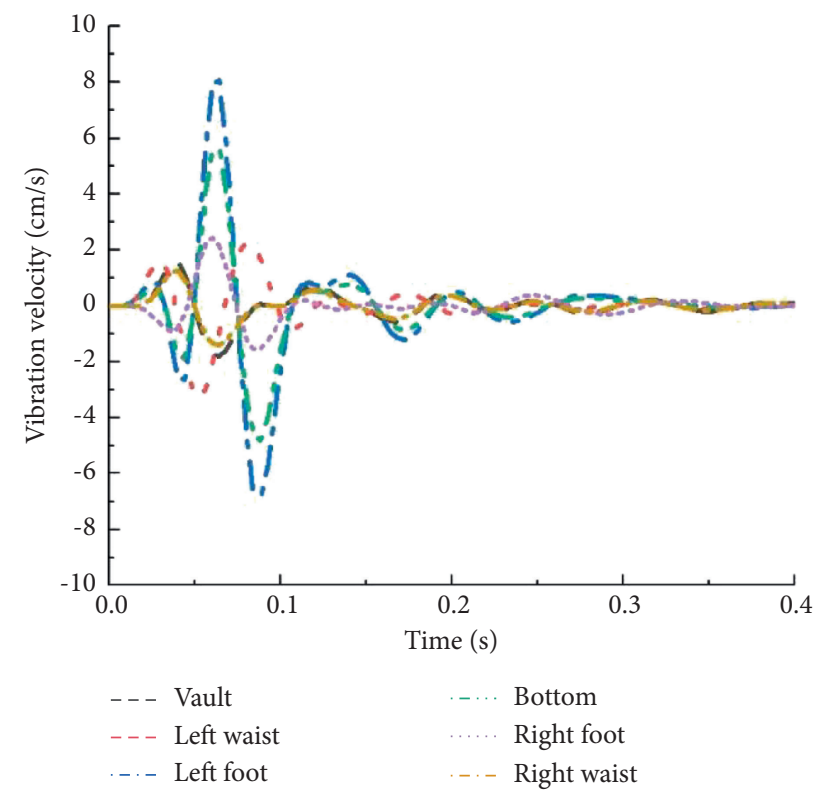

(a)

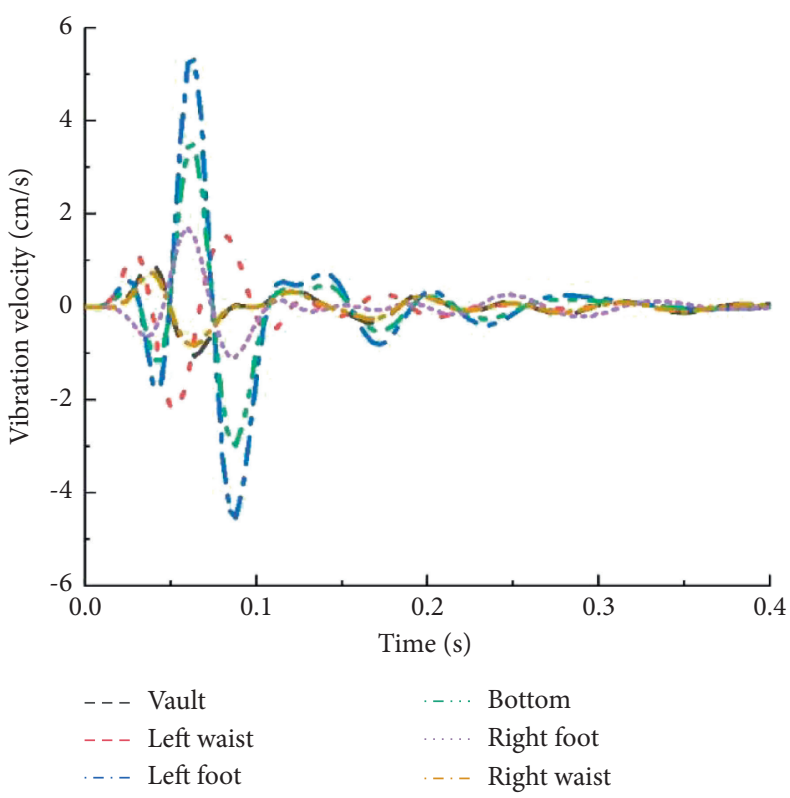

(b)

FIGURE 2: The vibration velocity-time history of different parts of the existing tunnel: (a) condition 1 and (b) condition 2. 


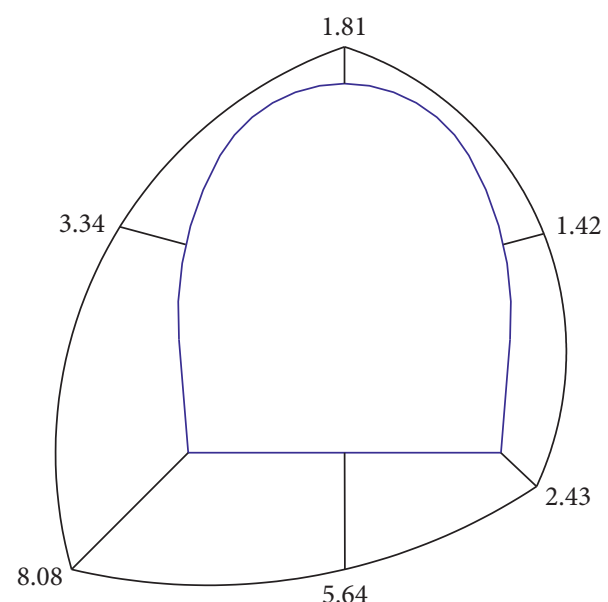

(a)

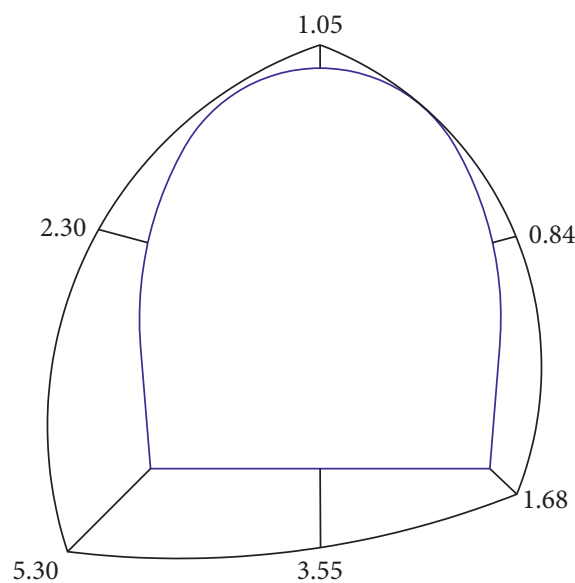

(b)

FIgURE 3: The envelope diagram of the vibration velocity of existing tunnel: (a) condition 1 and (b) condition 2.

values of $1.42 \mathrm{~cm} / \mathrm{s}$ and $0.84 \mathrm{~cm} / \mathrm{s}$. This is due to the fact that the left arch of the existing railway tunnel is mainly located on the front side of the blasting, while the right arch waist is mainly located on the back side of the blasting. Moreover, compared with full-section method, an obvious decrease of vibration velocity could be observed in the existing railway tunnel structure constructed with the bench method.

After that, the stress nephogram is chosen to compare the response of existing tunnel to the different blasting methods applied in the newly built tunnel, as shown in Figure 4. When the full-section method and the bench method are used for cutting blasting, the maximum stress of the existing railway tunnel lining structure appears at the left arch waists, which are $5.43 \mathrm{MPa}$ and $4.02 \mathrm{MPa}$, respectively. The minimum stress appears at the bottom of the tunnel lining structure, which are $0.25 \mathrm{MPa}$ and $0.31 \mathrm{Mpa}$, respectively. This is the effect of the redistribution of soil stress after the blasting action, and due to the principle of the arch effect of the Earth pressure, the tensile stress at the arch waists of the lining structure is the largest, and the tensile stress at the bottom of the tunnel is the smallest. The maximum stress value of different parts of the existing railway tunnel lining structure caused by the bench method cutting blasting is reduced by $25.97 \%$ compared with the full-section method, which is located on the left and right side of the tunnel. It can be found that the results obtained from the stress nephogram are consistent with the response law of vibration velocity.

Finally, the displacement nephograms of the lining structure are compared under different excavation methods, as shown in Figures 5 and 6. When the fullsection method and the bench method are used for cutting blasting, the maximum displacement caused by the blasting effect appears in the $Z$ direction, with the value of $5.92 \mathrm{~mm}$ and $5.85 \mathrm{~mm}$, respectively. The maximum $Y$ direction displacement is $3.14 \mathrm{~mm}$ and $3.10 \mathrm{~mm}$, and the maximum $X$-direction displacement is $0.73 \mathrm{~mm}$ and $0.88 \mathrm{~mm}$. It can be concluded that the vertical displacement of tunnel lining structure is more sensitive to the dynamic disturbance, but the influence of excavation methods is not so obvious.

4.2. Different Surrounding Rock Conditions. This section studies the influence of surrounding rock conditions on the response of existing tunnel to the blasting activities. The excavation method is specified as bench method, and the clear distance and cross angle between newly built and existing tunnels remain unchanged. Table 5 lists the vibration velocity, stress, and displacement of lining structure under different surrounding rock conditions. The similar law in the current simulation results could be found, the maximum vibration velocity and maximum stress both appear at the left arch foot, the minimum vibration velocity and stress appear at the right arch waist, and the maximum displacement occurs in the $Z$-direction. Compared with the IV-class surrounding rock, the tunnel built in the III-class surrounding rock tends to be more sensitive to the blasting activities in the newly built tunnel. This is because the III-class surrounding rock has better geological conditions and fewer joints and cracks in the stratum, the attenuation of blasting vibration waves is slower, and the adjacent tunnel structure responds more obviously to cutting blasting.

4.3. Different Spatial Relations. In this section, the effect of spatial relation (cross angles and clear distance) on the response of existing tunnel to the blasting activities is studied. The excavation method is specified as bench method, and the surrounding rock is specified as III-class. By the virtue of numerical simulation, the vibration velocity, stress, and displacement under different spatial relations are obtained.

The cross angles between the existing tunnel and newly built tunnel are set as $15^{\circ}, 30^{\circ}$, and $45^{\circ}$, and then the vibration velocity, lining stress, and displacement of structure are collected as shown in Table 6. The maximum vibration velocity all appears at the left foot of the existing tunnel 


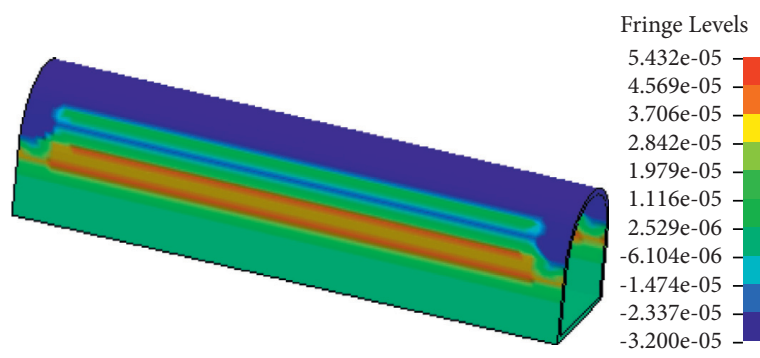

(a)

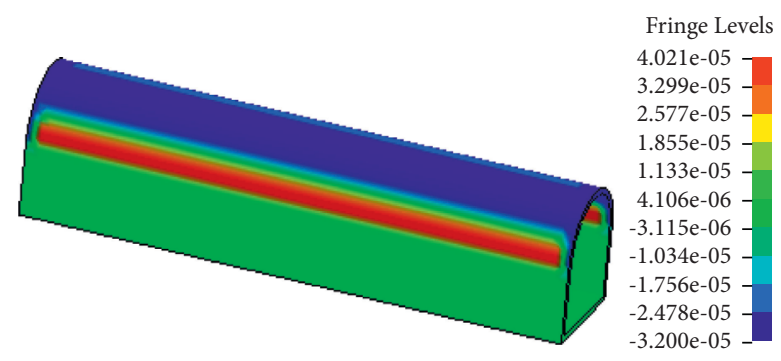

(b)

FIGURE 4: The lining stress of the existing tunnel: (a) condition 1 and (b) condition 2.

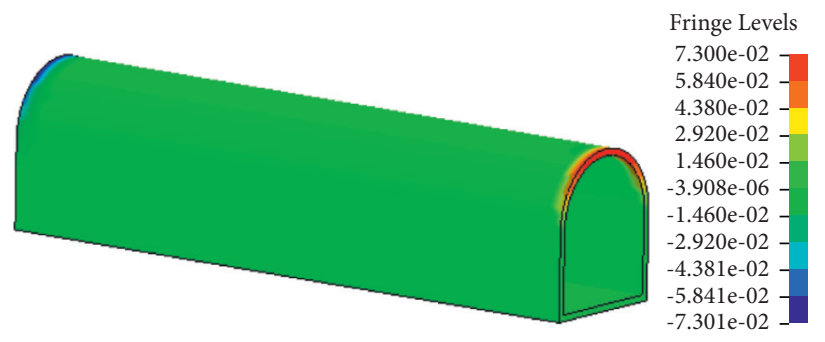

(a)

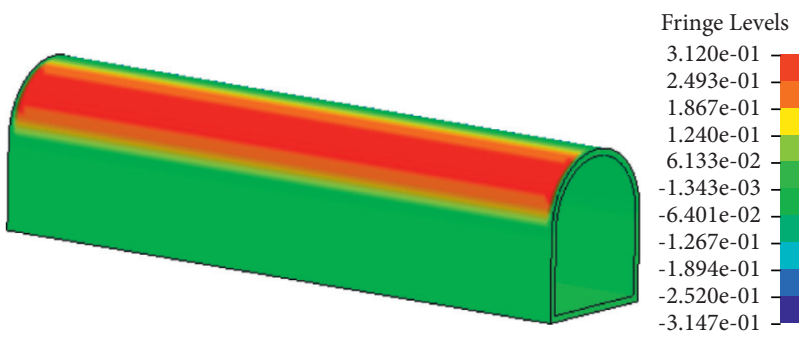

(b)

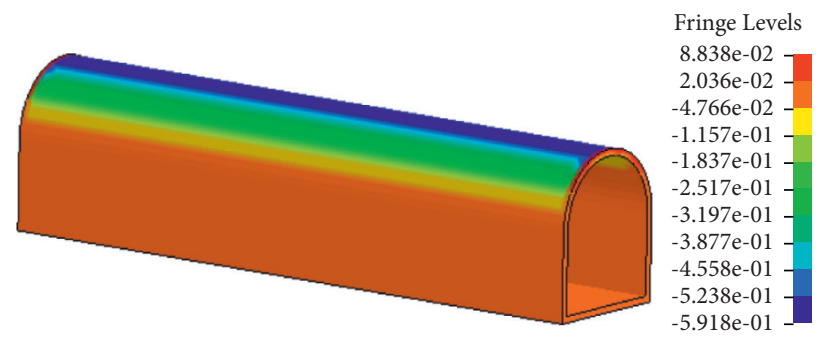

(c)

FIGURE 5: The displacement nephograms of the existing tunnel structure in condition 1.

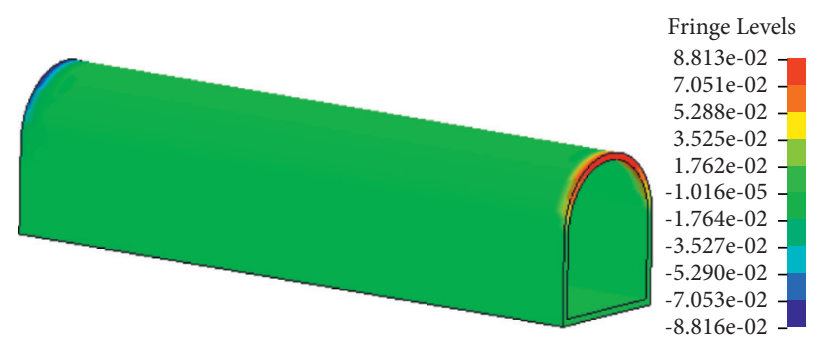

(a)

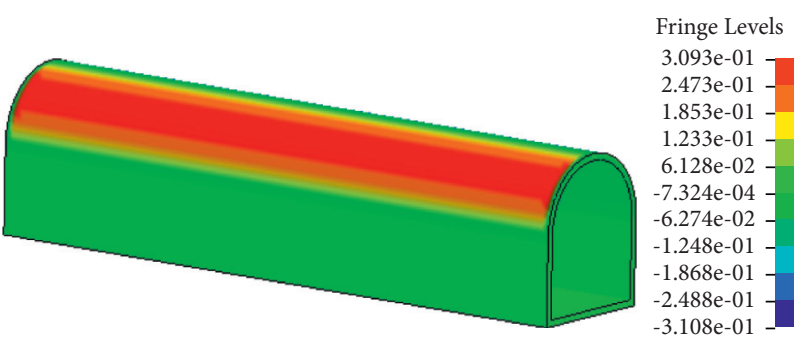

(b)

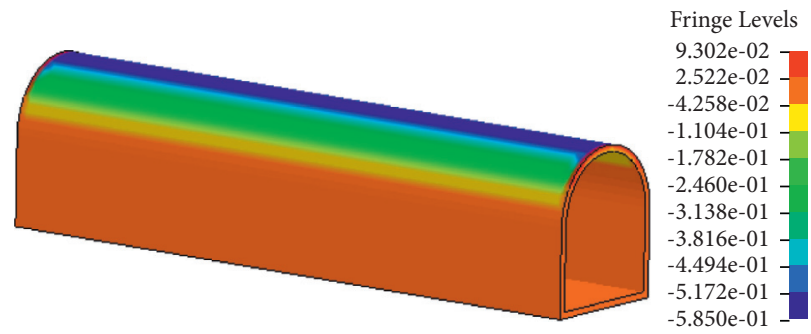

(c)

Figure 6: The displacement nephograms of the existing tunnel structure in condition 2. 
TABle 5: The dynamic response of the existing tunnel to blasting under different surrounding rock conditions.

\begin{tabular}{|c|c|c|c|c|c|c|c|}
\hline \multirow{2}{*}{$\begin{array}{l}\text { Items } \\
\text { Tunnel position }\end{array}$} & \multicolumn{2}{|c|}{$\begin{array}{l}\text { Vibration velocity } \\
\qquad(\mathrm{cm} / \mathrm{s})\end{array}$} & \multicolumn{2}{|c|}{ Lining stress $(\mathrm{MPa})$} & \multirow[b]{2}{*}{ Direction } & \multicolumn{2}{|c|}{ Displacement $(\mathrm{mm})$} \\
\hline & III & IV & III & IV & & III & IV \\
\hline Vault & 1.05 & 0.90 & -3.20 & -3.20 & \multirow{2}{*}{$X$} & \multirow{2}{*}{0.88} & \multirow{2}{*}{0.96} \\
\hline Left waist & 2.30 & 2.01 & 4.02 & 3.94 & & & \\
\hline Left foot & 5.30 & 4.95 & 1.13 & 1.06 & \multirow{2}{*}{$Y$} & \multirow{2}{*}{3.10} & \multirow{2}{*}{3.09} \\
\hline Bottom & 3.55 & 3.22 & 0.21 & 0.20 & & & \\
\hline Right foot & 1.68 & 1.42 & 1.13 & 1.06 & \multirow{2}{*}{$Z$} & \multirow{2}{*}{5.85} & \multirow{2}{*}{5.82} \\
\hline Right waist & 0.84 & 0.75 & 4.02 & 3.94 & & & \\
\hline
\end{tabular}

TABLe 6: The dynamic response of the existing tunnel to blasting under different cross angle conditions.

\begin{tabular}{|c|c|c|c|c|c|c|c|c|c|c|}
\hline \multirow{2}{*}{$\begin{array}{l}\text { Items } \\
\text { Tunnel position }\end{array}$} & \multicolumn{3}{|c|}{ Vibration velocity $(\mathrm{cm} / \mathrm{s})$} & \multicolumn{3}{|c|}{ Lining stress $(\mathrm{MPa})$} & \multicolumn{4}{|c|}{ Displacement $(\mathrm{mm})$} \\
\hline & 15 & 30 & 45 & 15 & 30 & 45 & Direction & 15 & 30 & 45 \\
\hline Vault & 1.34 & 1.05 & 0.68 & -3.20 & -3.20 & -3.20 & & & & \\
\hline Left waist & 2.68 & 2.30 & 2.01 & 4.60 & 4.02 & 3.52 & $X$ & 0.80 & 0.88 & 1.30 \\
\hline Left foot & 5.95 & 5.30 & 4.66 & 1.65 & 1.13 & 0.51 & & & & \\
\hline Bottom & 4.25 & 3.55 & 2.85 & 0.32 & 0.21 & 0.16 & $Y$ & 3.10 & 3.10 & 3.15 \\
\hline Right foot & 2.12 & 1.68 & 1.22 & 1.66 & 1.13 & 0.51 & 7 & & & \\
\hline Right waist & 0.98 & 0.84 & 0.72 & 4.45 & 4.02 & 3.52 & $Z$ & 5.88 & 5.85 & 5.83 \\
\hline
\end{tabular}

structure under three conditions. When the cross angle increases from $15^{\circ}$ to $45^{\circ}$, the maximum vibration velocity decreases by $22 \%$. The considerable lining stress occurs at the left arch waist and right arch waist, and the obvious decrease can be also found for lining stress with the variation of cross angle. For the index of the displacement of tunnel structure, the maximum values occur in the $Z$-direction, but the cross angle has little influence on such index.

Then the effect of clear distance between the existing tunnel and newly built tunnel on the dynamic response of the existing tunnel structure is studied. In the current simulating process, the new tunnel is excavated by the bench method, the surrounding rock condition is set as III-class, the cross angle is set as $30^{\circ}$, the clear distance is set as $8.45 \mathrm{~m}$, $16.90 \mathrm{~m}$, and $25.35 \mathrm{~m}$, respectively. After the calculation of the above numerical model under three different conditions, the vibration velocity, lining stress, and structure displacement were collected as shown in Table 7 . It can be found that the distribution of three indexes is similar to the above research results, the maximum vibration velocity appears at the left foot, the maximum lining stress occurs at the arch waist, and the maximum displacement happens in $Z$-direction. Moreover, the clear distance is proved to be significant for weakening the dynamic response of the existing tunnel to the blasting activities.

\section{Optimal Indicator of the Dynamic Response}

In this section, the blasting methods, surrounding rock conditions, cross angle, and clear distance are selected to distinguish the optimal index to indicate the dynamic response of the existing tunnel to blasting activities. Hence, the analytic hierarchy process is applied to calculate the contribution weight of the vibration velocity $P_{1}$, the lining stress $P_{2}$, and the structure displacement $P_{3}$ (scheme layer) to the dynamic response of existing tunnel (target layer). The detailed analytic hierarchy process is arranged as follows [27-30].

5.1. Establishment of Hierarchical Model. The model is composed of three layers, as shown in Figure 7. The top layer is used to select the optimal indicator I. The bottom layer consists of the vibration velocity $P_{1}$, the lining stress $P_{2}$, and the structure displacement $P_{3}$ of the existing tunnel. The intermediate layer consists of the blasting methods $R_{1}$, surrounding rock conditions $R_{2}$, cross angle $R_{3}$, and clear distance $R_{4}$.

5.2. Construction of the Judgement Matrix. The importance of the blasting methods $R_{1}$, surrounding rock conditions $R_{2}$, cross angle $R_{3}$, and clear distance $R_{4}$ to the optimal indicator I is compared on the basis of the published literatures [20, 31-39]. Combined with Saaty's scale table, the judgement matrixes are constructed as follows:

$$
A_{4 \times 4}=\left[\begin{array}{cccc}
1 & 5 & 5 & 3 \\
\frac{1}{5} & 1 & 1 & \frac{1}{5} \\
\frac{1}{5} & 1 & 1 & \frac{1}{5} \\
\frac{1}{3} & 5 & 5 & 1
\end{array}\right] .
$$

5.3. Hierarchical Single Sorting and Consistency Check. Through the transformation of matrix, the maximum eigenvalue is calculated to be 4.1545 , and the corresponding 
TABle 7: The dynamic response of the existing tunnel to blasting under different clear distance conditions.

\begin{tabular}{|c|c|c|c|c|c|c|c|c|c|c|}
\hline \multirow{2}{*}{$\begin{array}{l}\text { Items } \\
\text { Tunnel position }\end{array}$} & \multicolumn{3}{|c|}{ Vibration velocity $(\mathrm{cm} / \mathrm{s})$} & \multicolumn{3}{|c|}{ Lining stress $(\mathrm{MPa})$} & \multicolumn{4}{|c|}{ Displacement (mm) } \\
\hline & 8.45 & 16.90 & 25.35 & 8.45 & 16.90 & 25.35 & Direction & 8.45 & 16.90 & 25.35 \\
\hline Vault & 1.45 & 1.05 & 0.26 & -3.20 & -3.20 & -3.20 & \multirow{2}{*}{$X$} & \multirow{2}{*}{1.71} & \multirow{2}{*}{0.88} & \multirow{2}{*}{1.12} \\
\hline Left waist & 3.54 & 2.30 & 1.29 & 5.32 & 4.02 & 2.90 & & & & \\
\hline Left foot & 8.64 & 5.30 & 3.10 & 1.48 & 1.13 & 0.46 & \multirow{2}{*}{$Y$} & \multirow{2}{*}{3.25} & \multirow{2}{*}{3.10} & \multirow{2}{*}{3.10} \\
\hline Bottom & 5.76 & 3.55 & 2.06 & 0.35 & 0.21 & 0.08 & & & & \\
\hline Right foot & 2.45 & 1.68 & 0.91 & 1.48 & 1.13 & 0.46 & \multirow[b]{2}{*}{$Z$} & \multirow{2}{*}{6.00} & \multirow{2}{*}{5.85} & \multirow[b]{2}{*}{5.81} \\
\hline Right waist & 1.26 & 0.84 & 0.38 & 5.32 & 4.02 & 2.90 & & & & \\
\hline
\end{tabular}

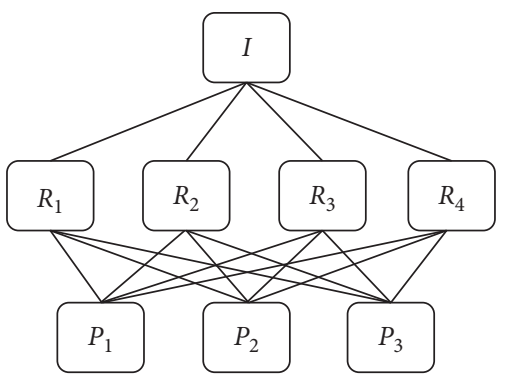

FIGURE 7: Hierarchical model of index for determining the optimal indicator of dynamic response.

eigenvector is extracted as $W=[0.8564,0.1246,0.1246,0.4853]^{T}$; after the normalization, the above vector is presented as $w=[0.5383,0.0783,0.0783,0.3050]^{T}$. Hence, the consistency index is calculated as CI $=(\lambda-n) /(n-1)=(4.1545-4) /(4-1)=$ 0.0515 , and the random consistency index RI is determined as 0.90 . Consequently, the consistency rate of the hierarchical single arrangement of the order $\mathrm{CR}=\mathrm{CI} / \mathrm{RI}=0.0515$ / $0.90=0.0572<0.10$, which means the order passes the consistency check.

5.4. Hierarchical Total Sorting and Consistency Check. Firstly, the importance of four factors, $R_{1}, R_{2}, R_{3}$, and $R_{4}$, in intermediate layer to the target $I$ in top layer is assumed as $r_{1}$, $r_{2}, r_{3}$, and $r_{4}$, respectively, the importance of three factors, $P_{1}$, $P_{2}$, and $P_{3}$, to the target $R_{j}$ in the intermediate layer is assumed as $p_{1 j}, p_{2 j}, p_{3 j}(j=1,2,3,4)$. Hence, the hierarchical total sorting of the bottom layer can be calculated though the factors' contribution to the overall target $\left(\sum_{j=1}^{4} r_{j} p_{i j}\right)$.

Then the consistency check is carried out following the step of consistency check in the single sorting. The importance of the vibration velocity $P_{1}$, the lining stress $P_{2}$, the structure displacement $P_{3}$, the factors $R_{1}, R_{2}, R_{3}, R_{4}$ in intermediate layer, and, the judgement matrixes are listed as follows:

$$
B_{3 \times 3}^{1}=\left[\begin{array}{ccc}
1 & 5 & 3 \\
\frac{1}{5} & 1 & 1 \\
\frac{1}{3} & 1 & 1
\end{array}\right] \text {, }
$$

$$
\begin{aligned}
& B_{3 \times 3}^{2}=\left[\begin{array}{lll}
1 & 3 & 3 \\
\frac{1}{3} & 1 & 1 \\
\frac{1}{3} & 1 & 1
\end{array}\right], \\
& B_{3 \times 3}^{3}=\left[\begin{array}{lll}
1 & 3 & 3 \\
\frac{1}{3} & 1 & 1 \\
\frac{1}{3} & 1 & 1
\end{array}\right], \\
& B_{3 \times 3}^{4}=\left[\begin{array}{lll}
1 & 5 & 3 \\
\frac{1}{5} & 1 & 1 \\
\frac{1}{3} & 1 & 1
\end{array}\right] .
\end{aligned}
$$

After computing the maximum characteristic roots, the corresponding weight vectors are calculated as $w_{1}^{3}$ $=[0.6586,0.1562,0.1852]^{T}, \quad w_{2}^{3}=[0.6000,0.2000,0.2000]^{T}$, $w_{3}^{3}=[0.6000,0.2000,0.2000]^{T}$, and $w_{4}^{3}=[0.6586,0.1562,0.1852]^{T}$. Then the combined weight of $P_{1}, P_{2}$, and $P_{3}$ to the target $R_{j}$ in the intermediate layer is calculated as $0.6494,0.1631$, and 0.1875 , and the corresponding weight vector is determined as $[0.6494,0.1631,0.1875]^{T}$. Consequently, the consistency rate of the hierarchical overall arrangement of the order $\mathrm{CR}=\mathrm{CI} /$ $\mathrm{RI}=0.0212<0.10$ means the assumed order meets the requirements of the consistency check. That is, the vibration velocity is the optimal index for indicating the dynamic response of existing tunnel to the blasting activities. Actually, the Safety Technical Specification for Blasting Vibration of Railway Engineering also adopts the vibration velocity as the safety index of existing structure and points out that the vibration velocity of single-line railway tunnel should be controlled lower than $6.0 \mathrm{~cm} / \mathrm{s}$, which is consistent with the methods adopted in the practical engineering.

\section{Conclusions}

In this study, the effect of the blasting activities on the existing tunnel structure is analyzed by the way of numerical simulation. The blasting methods, surrounding rock condition, cross angle, and clear distance are selected as four influence factors for the dynamic response of the existing 
tunnel, and the vibration velocity, lining stress, and the displacement of structure are selected to evaluate the safety condition of the existing tunnel when suffering the blasting loads. After that, the analytic hierarchy process is adopted to choose the optimal index to indicate the dynamic response of the existing tunnel to blasting activities. The main conclusions can be summarized as follows:

(1) From the results of the numerical simulation, the dynamic response of existing tunnel is proved to be highly relevant to the blasting methods, surrounding rock condition, cross angle, and clear distance. The dynamic response tends to be stronger with the increase of maximum charge per delay, the better surrounding rock condition, and the decrease of cross angle and clear distance.

(2) Comparing the dynamic response of different parts of existing tunnel structure, the maximum vibration velocity always appears at the left foot, the maximum lining stress always occurs at the left and right arch waist, and the maximum displacement always appears in the $Z$-direction. Hence, the above results can be referred to for development of the protective guideline of tunnel structure which is near to the blasting activities.

(3) Combined with the analytic hierarchy process and numerical simulation results, the vibration velocity is picked as the optimal index to indicate the dynamic response of the existing tunnel to blasting activities, which is consistent with most safety control specification of tunnel structure.

\section{Data Availability}

The data used to support the findings of this study are included within the article.

\section{Conflicts of Interest}

The authors declare that they have no conflicts of interest.

\section{Acknowledgments}

This work was supported by the Science and Technology Project of Hebei Provincial Department of Transportation (YC201907).

\section{References}

[1] X. Zhang, W. Zhang, and P. T. W. Lee, "Importance rankings of nodes in the China railway express network under the belt and road initiative," Transportation Research Part A: Policy and Practice, vol. 139, pp. 134-147, 2020.

[2] Q. Sun, X. Guo, W. Jiang, D. Haiying, L. Tingzhen, and $\mathrm{X}$. Xingbo, "Exploring the node importance and its influencing factors in the railway freight transportation network in China," Journal of Advanced Transportation, vol. 2019, Article ID 1493206, 16 pages, 2019.

[3] Z. Zhang, W. Xu, W. Nie, and L. Deng, "DEM and theoretical analyses of the face stability of shallow shield cross-river tunnels in silty fine sand," Computers and Geotechnics, vol. 130, Article ID 103905, 2021.

[4] M. Wang, J. Guo, L. Luo et al., "Study of critical buried depth of large cross-section loess tunnel for high speed railway," Rock and Soil Mechanics, vol. 31, no. 4, pp. 1157-1162, 2010.

[5] P. Tao, "Case study on design of a railway tunnel crossing underneath an existing highway tunnel with a small angle," Tunnel Construction, vol. 07, 2013.

[6] B. L. Wei, "Construction technology for Wenfu railway Guantouling tunnel under crossing the highway tunnel," Chinese Journal of Underground Space and Engineering, vol. 4, 2007.

[7] L. Wu, X. Zhang, Z. Zhang, and W. Sun, “3D discrete element method modelling of tunnel construction impact on an adjacent tunnel," KSCE Journal of Civil Engineering, vol. 24, no. 2, pp. 657-669, 2020.

[8] P. Ye, X. Yang, B. L. Ling et al., "Vibration effects on existing tunnel induced by blasting of an adjacent cross tunnel," Rock and Soil Mechanics, vol. 32, no. 2, pp. 537-541, 2011.

[9] Y. L. Gui, Z. Y. Zhao, L. B. Jayasinghe, H. Y. Zhou, A. T. C. Goh, and M. Tao, "Blast wave induced spatial variation of ground vibration considering field geological conditions," International Journal of Rock Mechanics and Mining Sciences, vol. 101, pp. 63-68, 2018.

[10] A. De, T. F. Zimmie, and K. E. Vamos, "Centrifuge experiments to study surface blast effects on underground pipelines," in Proceedings of the Pipeline Division Specialty Conference 2005, pp. 362-370, TX, USA, August 2005.

[11] J. B. Martino and N. A. Chandler, "Excavation-induced damage studies at the underground research laboratory," International Journal of Rock Mechanics and Mining Sciences, vol. 41, no. 8, pp. 1413-1426, 2004.

[12] T. Wang, Z. Song, J. Yang, J. Wang, and X. Zhang, "Experimental research on dynamic response of red sandstone soil under impact loads," Geomechanics and Engineering, vol. 17, no. 4, pp. 393-403, 2019.

[13] B. Duan, H. Xia, and X. Yang, "Impacts of bench blasting vibration on the stability of the surrounding rock masses of roadways," Tunnelling and Underground Space Technology, vol. 71, pp. 605-622, 2018.

[14] W. Lu, J. Yang, M. Chen, and C. Zhou, "An equivalent method for blasting vibration simulation," Simulation Modelling Practice and Theory, vol. 19, no. 9, pp. 2050-2062, 2011.

[15] S. G. Chen and J. Zhao, "A study of UDEC modelling for blast wave propagation in jointed rock masses," International Journal of Rock Mechanics and Mining Sciences, vol. 35, no. 1, pp. 93-99, 1998.

[16] D. J. Armaghani, M. Hajihassani, E. T. Mohamad, A. Marto, and S. A. Noorani, "Blasting-induced flyrock and ground vibration prediction through an expert artificial neural network based on particle swarm optimization," Arabian Journal of Geosciences, vol. 7, no. 12, pp. 5383-5396, 2014.

[17] M. Khandelwal and T. N. Singh, "Prediction of blast-induced ground vibration using artificial neural network," International Journal of Rock Mechanics and Mining Sciences, vol. 46, no. 7, pp. 1214-1222, 2009.

[18] Z. Y. Hong, Study on Dynamic Influence of Existing Highway Tunnel Caused by Blasting Construction of Diversion Tunnel Passing under it, Chongqing Jiaotong University, Chongqing, China, 2018, in Chinese.

[19] D. Z. Liu, Q. C. Gao, and X. Y. Wang, "Study on blasting vibration characteristics of up and down cross tunnels," Transactions of Beijing Institute of Technology, vol. 40, no. 12, pp. 1267-1274, 2020. 
[20] S. Song, S. Li, L. Li et al., "Model test study on vibration blasting of large cross-section tunnel with small clearance in horizontal stratified surrounding rock," Tunnelling and Underground Space Technology, vol. 92, Article ID 103013, 2019.

[21] R. Nateghi, M. Kiany, and O. Gholipouri, "Control negative effects of blasting waves on concrete of the structures by analyzing of parameters of ground vibration," Tunnelling and Underground Space Technology, vol. 24, no. 6, pp. 608-616, 2009.

[22] P. K. Singh and M. P. Roy, "Damage to surface structures due to blast vibration," International Journal of Rock Mechanics and Mining Sciences, vol. 47, no. 6, pp. 949-961, 2010.

[23] J. H. Zhang, L. Guo, Y. C. Zheng et al., "Influence and countermeasure analysis on urban tunneling near buildings," Journal of Railway Engineering Society, vol. 33, no. 4, pp. 95-100, 2016.

[24] M. Tian, D. Zhang, G. Qu et al., "Research on influence zoning of tunnel side crossing existing urban roads based on ultimate shear strain failure criterion," IOP Conference Series: Materials Science and Engineering, vol. 741, no. 1, 2020.

[25] J. O. Hallquist, LS-DYNA Keyword User's Manual, Livermore Software Technology Corporation, Livermore, CA, USA, 2007.

[26] J. Henrych and R. Major, The Dynamics of Explosion and its Use, Elsevier, Amsterdam, Netherland, 1979.

[27] B. L. Golden, E. A. Wasil, and P. T. Harker, The analytic hierarchy process, Vol. 2, Applications and Studies, Berlin, Heidelberg, 1989.

[28] T. L. Saaty, "How to make a decision: the analytic hierarchy process," Interfaces, vol. 24, no. 6, pp. 19-43, 1994.

[29] O. S. Vaidya and S. Kumar, "Analytic hierarchy process: an overview of applications," European Journal of Operational Research, vol. 169, no. 1, pp. 1-29, 2006.

[30] T. L. Saaty, "Decision making with the analytic hierarchy process," International Journal of Services Sciences, vol. 1, no. 1, pp. 83-98, 2008.

[31] Z. Zhang, C. Zhou, A. Remennikov, T. Wu, S. Lu, and Y. Xia, "Dynamic response and safety control of civil air defense tunnel under excavation blasting of subway tunnel," Tunnelling and Underground Space Technology, vol. 112, Article ID 103879, 2021.

[32] Z. G. Zhu, M. L. Sun, Y. Q. Zhu et al., "Field monitoring on blasting vibration and dynamic response of ultra-small spacing tunnels," Rock and Soil Mechanics, vol. 33, no. 12, pp. 3747-3752, 2012.

[33] L. P. Li, S. C. Li, Q. S. Zhang et al., "Analysis of dynamic response on blasting excavation of close-spaced tunnel," Journal of Highway and Transportation Research and Development, vol. 7, no. 148, 2008.

[34] B. Duan, W. Gong, G. Ta, Y. Xuxu, and Z. Xuewei, "Influence of small, clear distance cross-tunnel blasting excavation on existing tunnel below," Advances in Civil Engineering, vol. 2019, Article ID 4970269, 16 pages, 2019.

[35] X. Xia, H. B. Li, J. C. Li, B. Liu, and C. Yu, "A case study on rock damage prediction and control method for underground tunnels subjected to adjacent excavation blasting," Tunnelling and Underground Space Technology, vol. 35, pp. 1-7, 2013.

[36] R. Nateghi, "Prediction of ground vibration level induced by blasting at different rock units," International Journal of Rock Mechanics and Mining Sciences, vol. 48, no. 6, pp. 899-908, 2011.

[37] F. Xue, C. Xia, G. Li, J. Baocheng, H. Yongwang, and F. Yapeng, "Safety threshold determination for blasting vibration of the lining in existing tunnels under adjacent tunnel blasting," Advances in Civil Engineering, vol. 2019, Article ID 8303420, 10 pages, 2019.

[38] C. Dai, H. Sui, and C. Ma, "Study on the vibration effect of short footage blasting load on surrounding rock-support structure of tunnel," Shock and Vibration, vol. 2020, Article ID 8829349, 15 pages, 2020.

[39] Z. S. Wu, G. Q. Chen, K. Zen, K. Kasama, and D. L. Wang, "Effect of blasting on the adjacent underground tunnels," Applied Mechanics and Materials, vol. 90-93, pp. 1870-1878, 2011. 